\title{
EL GRUPO VALENCIANO Y EL REFORMISMO DE JOAQUIN LORENZO VILLANUEVA ANTERIOR A LAS CORTES DE CADIZ
}

\author{
VICENTE LEÓN NAVARRO
}

La figura de Joaquín Lorenzo Villanueva ha sido estudiada, fundamentalmente, en relación con su actividad en las Cortes de Cádiz. ${ }^{1}$ No hay duda que realizó un gran papel como diputado, a pesar de las controversias surgidas en torno suyo. ${ }^{2}$ Ahora bien, creemos que para comprender esta etapa de su vida hay que tener presente su formación anterior y su toma de postura

1 JoAquin LoREnzo VillanUEVA ha sido objeto de diversos estudios monográficos o parciales. Por no mencionar todos subrayaremos solamente algunos. Así, LABOA, J. S., Doctrina canónica del Dr. Villanueva. Su actuación en el conflicto entre la Sarita Sede y el Gobierno de España (1820-1823), Victoriense, 5, Vitoria, 1957. Haro, J. L., Pensamiento político religioso de Joaquín Lorenzo Villanueva, diputado en las Cortes de Cádiz, (1810-1823), Tesina leída en la Facultad de Teología de Valencia, Valencia 1960, ibid., La formación intelectual de Joaquín Lorenzo Villanueva. Ilustración valenciana y regalismo cortesano, Tesina leida en la Universidad de Valencia, Valencia, 1973. La PARRA, E., Política religiosa de las Cortes de Cádiz (1810-1813), Tesis doctoral inédita leida en la Universidad de Valencia, 1980. También a este tema han dedicado páginas Menéndez Pelayo, Mestre, Tomsich... entre otros.

2 LABOA, J. S., Doctrina canónica... Este autor ha estudiado a Villanueva aunque no con toda la objetividad que merece. Señala: "Para regalistas y jansenistas fue un sabio, un político avisado y además un santo sacerdote. Para sus enemigos en el campo de la política y de la literatura fue un ambicioso rastrero". Son importantes los juicios de ToMsicH, M. G., en El jansenismo en España. Estudio sobre las ideas religiosas en la segunda mitad del siglo XVIII, Madrid, 1972. Por su parte MESTRE, A., en Los humanistas españoles del XVI en la religiosidad de los llustrados valencianos, HISPANIA SACRA, XXXIII, 1981, señala la importancia de nuestros clásicos del XVI en la formación de Villanueva. 
decidida por la línea reformista que poco a poco, desde principios del siglo XVIII, ganaba posiciones dentro de la Iglesia y de la sociedad española y que a él, personalmente, le traería disgustos tanto en el seminario de Orihuela como en el de Salamanca, según luego veremos. De ahí, pues, que su trabajo como diputado sea el resultado y el fruto de este ambiente reformista dentro del cual hay que encuadrarlo.

No pretendemos, por tanto, hacer un estudio completo de su vida. Más bien nos centraremos en su obra y en sus ideas hasta las Cortes de Cádiz y como parte de un estudio más amplio en torno a la espiritualidad del siglo XVIII.

Villanueva estará directamente unido al grupo valenciano $y$, de forma especial, a Felipe Bertrán, obispo de Salamanca e Inquisidor General. De ahí que esta vinculación sea de enorme importancia para comprender a este personaje setabense; vinculación que no perderá a lo largo de su vida. Entre las figuras que más influirán sobre él, en su etapa universitaria, hay que destacar a Vicente Blasco y a Juan Bautista Muñoz. A este último dedicará grandes elogios:

En Játiva estudié las humanidades a estilo grotesco, según el plan miserable que regía en aquella época y de cuyo naufragio se salvaron pocos... No tuve una buena alma que me inspirase gusto, ni me mostrase el camino por donde a él se llega, hasta que en la Universidad di en manos de mi catedrático de Filosofía, D. Juan Bautista Muñoz, el escritor de la Historia del nuevo Mundo, uno de los españoles más doctos del siglo pasado, consumado filósofo y político, ciceroniano en el lenguaje y de vasta doctrina, como lo acreditan las Disertaciones con que enriqueció la edición que hizo en Valencia de Fr. Luis de Granada; azote del ergotismo escolástico, que ya entonces empezaba en España a perder el pleito. Este fue más adelante mi director y mecenas en Madrid. ${ }^{3}$

Muñoz en íntima relación con Mayáns, fue quien se encargó de editar las obras latinas de fray Luis de Granada, acompañadas de prólogos personales que analizan la situación del clero,

3 Villanueva, J. L., Vida literaria o Memoria de sus escritos y de sus opiniones eclesiásticas, políticas y de algunos sucesos notables de su tiempo, con un apéndice de documentos relativos a la historia del Concilio de Trento, escrita por el mismo..., Londres, 1825. 
de la predicación, de los planes de estudio, etc. Este hombre abierto, intelectual y enemigo de la escolástica, jugó un gran papel en la educación de Lorenzo Villanueva ${ }^{4}$ y en la apertura de nuevas sendas del saber, amor a los clásicos, a los autores modernos, desprecio por el ergotismo escolástico, crítica histórica, atracción por los clásicos españoles del siglo XVI... Lo cierto es que bajo las enseñanzas de su maestro, Villanueva emprende una vida intelectual importante. ${ }^{5}$ Su relación con Muñoz no cesará ya jamás. Así, cuando en 1781 llegue a Madrid será en su casa donde se hospede.

Bajo las directrices de este aprendizaje empezará sus primeros enfrentamientos con lo que hoy llamaríamos el «orden establecido". El primer incidente tendrá lugar en Orihuela donde había sido llamado por el obispo Tormo para ocupar una cátedra de filosofía en el Seminario. Tenía entonces dieciocho años. En Orihuela puso Villanueva sus esperanzas de proseguir su carrera eclesiástica. Mas su estancia se verá truncada debido a los duros enfrentamientos con sectores poco proclives a aceptar la pedagogía del de Játiva y tuvo que pasar a Madrid. La causa sería:

Dió motivo a esta imprevista determinación un tropiezo que me pusieron al fin de mi cátedra, con motivo de unas conclusiones preparadas para mis discípulos. Siempre atribuí este lance a especial protección de Dios, que por tan raro medio me preservó del escollo del fanatismo en que probablemente diera atendido el plan medio gótico de aquellos estudios eclesiásticos y los pocos o ningunos recursos que se me presentaban allí para no dar en es-

4 LABOA, J. S., Doctrina canónica..., 16. También indica que "de él -se refiere a Muñoz-, sin duda alguna tomó Villanueva el elegante y castizo saber de su prosa". Por su parte HARO SABATER, J., en La formación intelectual..., 35, dirá que "Villanueva estudia teología en un ambiente de efervescencia y polémica. Su universo intelectual queda constituido por el agustinismo y el rigorismo moral presentadas ambas doctrinas en oposición irreconciliable a las teorías de los jesuitas...

5 YeREgUI, J., Historia de la causa seguida en el Tribunal de la Inquisición contra el señor D. Josef Yeregui, Maestro honorario del Supremo Consejo de la misma Inquisición. Copia de la que formó el mismo Señor Yeregui, una y otra en Madrid en el año 1793, A. U. Va., Ms., 79. Teología Moral por el P. Félix Potestas y los Prolegómenos de la Santa Escritura por el jesuita Becano. "Y no ciñéndose mi deseo de saber de estas cosas, me entendia cuanto me era posible a la lectura de cuantos libros me vinieron a la mano; que a excepción de la Santa Biblia, Fr. Luis de Granada..., todos fueron malos...". 
te despeñadero. Goudin y Brilluart eran la leche de aquellos alumnos: preparábanse tambien para enseñarles los cánones por las instituciones de Valense el canónigo de Lorca, don Alejandro Ribas: de tal leche ¿qué quilo podía esperarse? El que aparecía en casi todos los Seminarios de España, a excepción del de Barcelona, dirigido por el sabio obispo Climent y el de Murcia y acaso algún otro que pudo escapar de los lobos que andaban entonces, aunque no tanto como ahora, en persecución de las buenas letras. ${ }^{6}$

Es duro, realmente, analizando la situación del Seminario de Orihuela y el escaso progreso en pro de las buenas letras que Tormo podría haber realizado. Malos libros, peor ambiente y ningún deseo de mejora, que juntamente con la imposibilidad de compaginar las nuevas corrientes de pensamiento que portaba Villanueva con el ambiente que allí existia, nos da las causas por las que el setabense no se afincó en el Seminario oriolano.

Señala Laboa que Villanueva ${ }^{7}$ llegó envenenado doctrinalmente y no sólo en doctrinas teológicas, sino sobre todo canónicas. Creemos que es exagerado tal juicio. Más bien, pensamos, se da un rechazo del orden establecido en el Seminario y que las nuevas ideas venían a subvertir. Por tanto, se trata de un simple proceso de defensa ante el "enemigo". Eso se desprende también de su relato: la burla que se hacía del probabilismo en la ciencia de las costumbres; vigencia del ergotismo escolástico que suplantaba a la Biblia, Santos Padres, Concilios y alimentando la idea del poder papal tanto en el orden espiritual como en el temporal:

En medio de estas tinieblas, cuyo horror no me espantaba aún entonces, procuraba inspirar a los alumnos de mi cátedra el tal cual desengaño en la lógica, en la moral y en la física que había debido a Muñoz y a otro catedrático que le sucedió, llamado don Josef Matamoros... Durante el curso ordené por encargo del obispo unas Instituciones Philosophicas, purgadas de la paja de aquella era; trabajo perdido, porque ni el obispo me las pidió luego, ni yo me convidé a dárselas. ${ }^{8}$

VILlanUeVa, J. L., Vida literaria..., 4-5.

LABOA, J. S., Doctrina canónica..., 18.

8 VillanueVa, J. L., Vida literaria..., 6. 
El esclarecimiento de este conflicto resultará difícil y pueden surgir diversidad de hipótesis. Nosotros, por el momento, no tenemos la solución. ¿Le resultó molesta también a Tormo la actividad de Villanueva? ¿Tuvo miedo a protegerle frente al resto? ¿Creyó, el obispo, que para evitar mayores males saliese del seminario y de Orihuela? ¿Tuvo la culpa Villanueva, llevado por la juventud de sus dieciocho años? La vida religiosa oriolana estaba tremendamente enrarecida, dominada por los regulares, anclados en el más puro ultramontanismo. Sin embargo el Obispo Tormo estaba unido al grupo reformista valenciano, mantenía correspondencia con Climent y pertenecía a un ambiente distinto, aunque no acometiera la reforma del Seminario hasta $1784 .^{9}$ Si el espíritu reformador del obispo está claro, ¿quiso, entonces, evitar problemas y permitir o aconsejar la salida de Villanueva? La verdad es que las relaciones acabaron enfriándose y la protección desapareció. Las mismas Instituciones que Tormo encomendara al joven profesor quedaron sin entregar. Luego se las presentaría a su maestro Muñoz, una vez que se hospedó en su casa de Madrid. A éste le parecieron buenas.

A partir del momento de su establecimiento en la Corte y en casa de su mecenas, el mundo social de Villanueva se amplía por las amistades del mismo Muñoz: Cerdá Aỷala, Montoya, Magí, Tavira, Pérez Bayer y Blasco que vivía con Muñoz. Es decir, todo un nuevo mundo de amplias posibilidades intelectuales y que encuentra su expresión más clara en el grupo "jansenista" que se mueve en torno a la condesa de Montijo. Según nos lo expone P. Demerson ${ }^{10}$ alli confluyen personajes como A. Palafox, Rodrigálvarez, Posada, Yeregui, Tavira, hermanos Cuesta, Pedro de Silva, Amat, Rossell y el mismo Villanueva, aparte de otros no eclesiásticos como Meléndez Valdés, Ayala, Jovellanos, Lugo..., dándose dentro del grupo una actividad intelectual muy importante y unas relaciones amistosas y de mutuas influencias, destacables. Con varios de ellos Villanueva mantendrá una amistad profunda, al igual que con la condesa.

9 Se trata de la reforma contenida en el Expediente sobre el Seminario, del año 1784. Los datos de este Expediente que utilizo, los debo a la amabilidad de Mario Martínez Gomis.

10 Demerson, P., María Francisca de Sales Portocarrero. (Condesa del Montijo). Una figura de la llustración, M., 1975. 
Un segundo hecho notable, por la relación que guarda con el de Orihuela, viene a sumarse a la vida del de Játiva. A consecuencia de unas oposiciones a las canongías de la real iglesia de San Isidro en la primavera de 1781:

Mi paisano el Inquisidor General, obispo de Salamanca, don Felipe Bertrán, a quien con razón da Llorente los títulos de sabio y santo, me nombró catedrático de teología de su Seminario de S. Carlos; de donde por otra borrasquilla que se me levantó de puertas adentro, volví luego a Madrid, so color de ir a ordenarme de presbitero a título de un préstamo. El R. Bertrán, que desde entonces se declaró mi protector, me hospedó en su casa, me nombró su capellán y consultor del tribunal de Corte y me tuvo en su compañía hasta la muerte, confiriéndome él mismo las órdenes y depositando en mi, a pesar de mis pocos años, muy íntima confianza. ${ }^{11}$

Observamos idéntico planteamiento que en su etapa de Orihuela aunque difiera la materia a explicar, filosofía entonces, teología ahora. Se puede pensar, y con razón, que la situación de los Seminarios de Orihuela y de Salamanca diferían notablemente. El último, más moderno, hechura del propio Bertrán, con unos planes de estudio más acordes a los tiempos, no es capaz tampoco de asimilar a Villanueva, aunque la uborrasquilla" de la que nos habla debió ser más individual y particular. De todas formas, la actitud de los obispos difiere mucho; mientras Tormo le "abandona», Bertrán le protege y deposita todo tipo de confianza en él. Y ello no debió ser exclusivamente por tratarse de un valenciano. En los últimos días de su vida pidió para el setabense la doctoral de la real capilla de la Encarnación de Madrid y, de aquí, saldria para capellán de honor y predicador del rey en 1795.

11 Villanueva, J. L., Vida literaria..., 35. A este respecto conviene señalar que la primera obra impresa de Villanueva, una traducción del Poema de San Próspero, ilustrado con notas suyas, está dedicado al obispo Bertrán. En el prólogo se lee: «He creído justo consagrarlo al esclarecido nombre de V. E. que con tanto ardiente celo, contribuye a que se renueve en nuestro siglo el espiritu de los primeros tiempos de la Iglesian. Citado también por HaRO, J., La formación intelectual..., 41-42. En Vida literaria..., 36, se lamenta del veto de que fue objeto a la muerte de Bertrán: "Se me encargó el sermón de exequias; el cual no se imprimió por el voto reservado de cierto orador amigo mío, de los muchos que suelen honrarse con este nombre y acaso no pasan de conocidos. De esta zancandilla no me quejé nunca...". 
a) Su obra y sus ideas

A través de su dilatada obra queremos exponer sus ideas fundamentales:

... a finales del reinado de Carlos III había empezado a publicar el año cristiano de España y las Dominicas y fiestas móviles con varias disertaciones litúrgicas y de disciplina eclesiástica: obra que comprende diecinueve volúmenes en 8 mayor. Procuré muy de veras que campease en ella la piedad a la par de la sólida crítica. De las vidas de los santos descarté las ficciones de las decretales de S. Isidoro Mercator y las fábulas de las crónicas publicadas por el jesuita Román de la Higuera, abortos ambos de la humana malignidad que tanta neguilla han introducido en la pura trox del derecho canónico y de la historia de la Iglesia. Sirviéronme en esto de guía, así la Censura de las historias fabulosas de Nicolás Antonio que publicó don Gregorio Mayáns y las disertaciones de Dormer y del Marqués de Mondéjar y la España Sagrada de los sabios agustinos Flórez y Risco, así como Fleury, Tillemont... ${ }^{12}$

Persigue, por tanto, una línea crítica, objetiva de la historia, que deseche cualquier falsedad para que no se acreciente la ignorancia del pueblo. Tal es el método que sigue. El tema de la ignorancia es fundamental. Con él se engarzan el de la predicación, el de la penitencia, el de la Sagrada Escritura, el de la relajación etc. Villanueva la analizará desde el erasmismo y a través de los clásicos del siglo XVI español, Luis de León y de Granada, Porras, Meneses, etc. Al tema de'la ignorancia, pues, dedica el prólogo del tomo III del Año Cristiano, manifestando que los españoles deben tener sus propias obras sin recurrir a los extranjeros, al tiempo que señala las causas de la ignorancia. El origen fundamental está en los libros de moral relajada y en la falta de preocupación que hay para impedir que la gente joven, los niños y niñas lleven en sus manos comedias y novelas nada honestas,

12 Ibíd., 73-74. Este es el fin que aparece en la obra Viaje literario..., en la que se busca la verdad histórica con el fin de ilustrar convenientemente a los fieles: "Los viajes literarios, tan justamente promovidos en nuestros días por lo mucho que contribuyen al fomento de las ciencias útiles a la sociedad, tienen una especial recomendación para los pueblos católicos cuando se dirigen a extender el conocimiento de la disciplina eclesiástica y a ilustrar en todo o en parte los ritos y prácticas religiosas de la Santa Iglesian. 
amén de leyendas perniciosas e inútiles y empleen los mejores años de su vida en tales menesteres, escuela de soberbia, de desenvoltura ${ }^{13}$ y fuente de veneno. ${ }^{14}$ Llama a la ignorancia de la doctrina cristiana, peste, y como tal es, por una parte, gravísima $y$, por otra, muy general: ${ }^{15}$

no sólo en las aldeas y pueblos cortos sino en las villas y ciudades grandes donde hierven los predicadores y están abiertos al parecer para todos los pastos de la doctrina cristiana. ${ }^{16}$

Este mal no es reciente, sino que viene de lejos y ha producido en el pueblo males sin límite. Frente a esta situación, Villanueva con similar planteamiento de Blasco en el Prólogo a los Nombres de Cristo de Fray Luis de León, y recordando a Mayáns en la Oración sobre la verdadera elocuencia, señala que era muy distinto el estilo que se guardaba en España cuando había hombres como San Ignacio de Loyola, Santo Tomás de Villanueva, Meneses, Castro, Luis de Granada, Avila y su escuela etc., y aun entonces se quejaban también de este mal, pero por lo menos, entendieron su gravedad y sus tristísimas consecuencias. $Y$ se pregunta Villanueva cómo es posible que esto suceda en un país como España, hija predilecta de la Iglesia, donde abundan mozos y mozas que es necesario catequizar como si se tratara de

13 Ibíd., 122. Indica cómo respecto a esto la Inquisición no se mostró exigente: "Iguales muestras de frialdad dio la inquisición en el orden a los corruptores de la moral evangélica. En cédula de 16 de junio de 1768 mandó Carlos III que la prohibición de la Inquisición se dirigiese, entre otras cosas, a condenar las opiniones laxas, contrarias a las buenas costumbres. Harto comunes eran, por desgracia, los libros donde se enseñaban estas miserias; apenas había bibliotecas públicas, y aún privadas de colegios y comunidades religiosas, donde no se hallasen las obras de los jesuitas Lacroix, Busembaum, Escobar y otros tales teológos que no parece haber tomado la pluma sino para canonizar la corrupción del corazón humano..." y continúa señalando cómo mientras estaban prohibidas.las obras de sana doctrina como las de Juenin, Obstraet, Natal Alejandro, etc., las otras circulaban libremente.

Villanueva, J. L., Año cristiano de España, 12 tomos, Madrid, 1791-1794.

Demerson, P., María Francisca de Sales..., 263, en carta a Clément exponía la Condesa del Montijo: "la Iglesia sigue resintiéndose de la ignorancia que ha reinado durante tanto tiempo en cuanto a las grandes y principales verdades de la religión, por culpa de la horrible proscripción de la Sagrada Escritura en lengua vulgar. A pesar de todo, la luz no se ha extinguido por completo...".

Villanueva, J. L., Año Cristiano, II. 
gentiles; siendo esto una grave enfermedad se mira con indiferencia ${ }^{17}$ sin hacer caso del remedio que está en la doctrina. Así trae el recuerdo de Luis de Granada, lamentándose:

¿Qué cosa más para llorar - decía Fray Luis de Granadaque ver tan desterrada esta luz del mundo? ¿Que ver tantas y tan palpables tinieblas? ¿Tanta ignorancia en los hijos? ¿Tanto descuido en los padres...? ${ }^{18}$

Los que se llaman cristianos viven, pues, falsamente, sin verdadero conocimiento de la doctrina. De ahí que lo que se sabe, se sabe de memoria, sin gusto, sin sentimiento ni consideración de lo que se ha aprendido. Por tanto, sigue Villanueva, se saben los nombres de las cosas pero no su contenido. Es ese quedarse en la corteza, sin profundizar en el interior. $Y$ en una línea totalmente erasmista pero a través de Granada - como un Bertrán, un Climent...- expondrá: ${ }^{19}$

Apenas hay moro ni judio, decia Fr. Luis de Granada (...) que si le preguntas por los principales artículos y partes de su ley, no sepa dar razón de ellos. Mas entre los cristianos (que por haber recibido la doctrina del cielo le habían de traer más impresa en lo íntimo de su corazón) hay tanto descuido y negligencia que no solamente los niños, mas aun los hombres de edad, apenas saben los elementos de esta celestial filosofía. ${ }^{20}$

17 Villanueva, J. L., Dominicas y fiestas movibles del año cristiano de España, Madrid.

18 Ibid.

19 No se alude directamente a Erasmo. Sin embargo la exposición seguida es erasmista. Esta forma de actuar de Villanueva y de tantos hombres del XVIII podría haber llevado a DominguEz ORTIZ, A., en Citas tardias..., a pensar que Erasmo no es conocido en el siglo XVIII. Esta conclusión como bien indica LóPEZ, F., en Juan Pablo Forner..., 129, es falsa, pués creemos que Erasmo está muy presente en este siglo y es conocido por los lilustrados, aunque no siempre aparezca citado expresamente. De ahí que recurran a autores erasmistas como en este caso Villanueva o en otras se tienda a "ridiculizar" al roterdano como Muñoz.

Dominguez Ortz, A., Citas tardías de Erasmo. Revista de Filología Española, XXXIX, (1955), 344-350.

LOPEZ, F., Juan Pablo Forner et la crise de la conscience espagnole au XVIII siécle, Burdeos, 1976.

20 Ibíd., III, y añade "¿Qué excusa alegaremos si se nos echa en cara que no sabemos de la Escritura lo que basta para conocer a Cristo? Esta ciencia altísima de la-religión es el estudio digno de los cristianos y no las vanas y profanas leyendas que vacian de Cristo el alma y lo llenan del mundon. 
¿Dónde está, entonces, el remedio? En principio en la lectura de las Sagradas Escrituras (como expone en De la lección de la Sagrada Escritura en lenguas vulgares) a las que tiene acceso el pueblo gracias al decreto del Inquisidor Bertrán. Medida del todo necesaria, a pesar de que puedan haber quienes piensen que el pueblo no está todavía preparado para poner en sus manos tales libros traducidos, alegando que pueden abusar de tal medida. Sin embargo con ellos se propaga la doctrina pura y se esparce la semilla de las buenas costumbres. Así, los fieles pueden acceder a un conocimiento total de sus obligaciones, porque:

Las Sagradas Escrituras dadas por Dios para enseñanza y consuelo nuestro, asi en el tiempo de la ley de Moisés como después de la muerte de Nuestro Señor Jesucristo, fueron miradas como pasto de los fieles, como muro contra los insultos de nuestras pasiones y como una armería de todo género en armas espirituales para vencer al mundo y al demonio. ${ }^{21}$

Y así sucedía cuando el pueblo tenía acceso a ellas. Con esto, todos, tanto hombres como mujeres y en cualquier estado, las tenían a mano y se aprovechaban de su uso, lectura y meditación. Su ausencia no puede traer sino degeneración tanto para el pueblo fiel como para el clero. A pesar de eso, hay muchos que desearian que estos males se diesen porque no se contentan con prohibir la Sagrada Escritura sino también quisieran que lo fuesen los piadosos escritos de Santa Teresa, Avila, Luis de Granada y otros semejantes, por la simple razón de contener textos de la Escritura. Libros y escritos que aparecieron, precisamente, por la prohibición de leer la Biblia en lengua vulgar, intentando así sustituir, en la medida de lo posible, tal defecto. También por esta ausencia surgieron catecismos como los de $\mathrm{Ca}$ rranza y Granada. Recurre Villanueva, constantemente, a nuestros clásicos del siglo XVI, con los que entronca perfectamente,

21 Ibid., De la lección de..., 1. También en Dominicas..., V, 329, dirá refiriéndose a este mismo tema que: "Mas como para alcanzar esta victoria no bastan armas ofensivas, por supuesto que en algunos lances estamos obligados a acometer y a destruir el error y el pecado, y a poner en fuga al demonio, nos arma el Apóstol de la palabra de Dios...". 
para defender sus ideas, sobre todo a Luis de León y de Granada, Carranza, Santo Tomás de Villanueva y también a los que desde principios de siglo venían abogando por esta lectura, especialmente Blasco, que, según Mestre, es necesario tener presente para entender la obra de Villanueva. ${ }^{22}$ Ya en el caso concreto de Granada, es el Prólogo Galeato una de las principales fuentes donde bebe el de Játiva y al que recurre constantemente, así como a otros escritos del mismo autor.

Esta defensa tan manifiesta de la Sagrada Escritura en lengua vulgar no gustó a todos. Concretamente a Guillermo Díaz Luzeredi, quien atacará a Villanueva. Este a su vez replicó profundizando en el tema que ya había expuesto anteriormente en defensa de la lectura de la Biblia. ${ }^{23}$ A la exposición de Luis de Granada, del que el setabense conocía bien sus obras, dedica la carta XXV. Su doctrina la toma, como ya se ha señalado, del Prólogo Galeato aunque haga esporádicas exploraciones en obras como Símbolo de la Fe o Doctrina Cristiana.

\section{b) Predicación y palabra de Dios}

No se puede separar de este contexto el papel que ha de desempeñar, en el caso concreto del clero, el conocimiento de las Sagradas Escrituras para hacer uso de ellas y alimentar al pueblo.

Conoce Villanueva la trayectoria de la predicación y sus defectos. Así, plantea qué es lo que ésta no debe ser. Hay predicadores que buscan el aplauso de los oyentes, es decir, predican para ganar honra y no para edificar, preparándose con estudio a lo más, pero no con oración. ${ }^{24}$ Son éstos los que profanan el mi-

22 Mestre, A., Religión y Cultura en el siglo XVIII, en "Historia de la Iglesia en España, vol. IV, la Iglesia en la España de los siglos XVII y XVIII", Madrid, BAC 1979, pp. 586-743.

23 Villanueva, J. L., Cartas eclesiásticas al doctor D. Guillermo Díaz Luzeredi en defensa de las leyes que autorizan ahora al pueblo para que lea en su lengua la Sagrada Escritura, Madrid, 1794. 
nisterio sirviéndose del altar para mantenerse. ${ }^{25}$ Pueden hablar muy bien, pero de qué les sirve si no les brota del corazón; más bien al contrario sale de los labios. Este tipo de predicadores debe ser reprobado porque todo su fin está puesto en admirar, en ganar aplauso, fama y dinero, pero no en edificar, por lo que las costumbres se corrompen cada día más y se pierde el gusto por las cosas divinas. Esto es, hay un rechazo por la predicación vacía de contenidos, por los penegíricos, por el ergotismo escolástico y latines de poca monta o verborrea literaria. La función del predicador es sencillamente predicar la palabra de Dios, que es ese cuchillo penetrante y agudo que taladra todo el hombre, se abre lugar hasta el corazón ${ }^{26}$ y es mensajera de la gracia, don de Dios. ${ }^{27}$ Por tanto, predicar esta palabra divina, es hablar palabras de Dios, es iluminar a los fieles para hacerles inteligibles las verdades de la salud, procurando ante todo la gloria de Dios y la conversión del hombre. ${ }^{28}$ Es fundamental que tal palabra sea eficaz, dé frutos. Por ello es necesario que el orador se prepare primero con el estudio y luego con la meditación, no confiando en sus propias fuerzas. ${ }^{29}$ Así vendrá a ser sabio y prudente. Pues es imposible que la ilustración y santificación de los fieles venga como consecuencia de la ociosidad y de la comodidad. Al contrario, los conocimientos y santidad son los que deben guiar a los fieles por el verdadero camino que es estrecho, único para alcanzar la salvación. Para que todo esto sea eficaz, el que predica se ha de acomodar en sus sermones a la capacidad y a la necesidad de sus oyentes, llevando el caudal del Antiguo y Nuevo Testamento a quienes le escuchan. Ha de identificarse con su doc-

Ibid., Dominicas..., V, 163.

Ibid., Año Cristiano, VI, día 24.

Ibid., Dominicas..., III, 114.

Ibid., II, 429.

Ibíd., V, 322. "Quién no reconoce en su propia flaqueza la necesidad de la oración y de la vigilancia cristiana? De dónde sino del Omnipotente nos puede venir el brio necesario para conservarnos dependientes de su gracia y obedientes a su ley? Ay del que en si espere hallar industria y fortaleza contra la astucia y furor del león infernal! Cierta es la victoria del diablo contra los que entran a luchar con él fiados en sus propias fuerzas y descuidados de recurrir a Dios». En este sentido Villanueva es consciente de la debilidad humana y de su poquedad. 
trina, esto es, que su celo, caridad y buenas obras sean el espejo de lo que predica, con lo que los fieles quedarán convencidos. Sin embargo, no debe dejarse llevar ni de la gente ni de sus posibles ideas acerca de lo que normalmente el pueblo, poco instruido, llama piedad, porque ésta suele ser falsa.

\section{c) La devoción interior-exterior}

La mayor parte de las veces la causa de la falsa devoción proviene del mismo clero:

Desde que fui promovido al sacerdocio, comenzó a darme en rostro la precipitación y falta de decoro con que celebraban la santa misa algunos presbíteros: hízome conocer mi mismo estado la enormidad de este desorden y el grave escándalo que de él se seguía a los demás fieles. Veía, por otra parte, que el vuelo que iba tomando, le hacía menos responsable a las personas que tenian autoridad para conseguirle; y que aun para algunos que pasaban plaza de virtuosos, habia llegado a hacerse intolerable una misa en veinte minutos. Habíalos de doce y aún de nueve: díjome don Blas del Caso, agente fiscal del Consejo de las Ordenes Militares que a dos presbíteros de su territorio se les acababa de procesar porque decían la misa el uno en siete minutos y el otro en cinco. ${ }^{30}$

El conocimiento de esta situación le indujo a escribir De la obligación de decir misa con circunspección y pausa y luego De la reverencia con que se debe asistir a la misa y de las faltas que en esto se cometen. En estas obras abunda en el tema de la ignorancia que se tiene sobre el sacrificio de la misa, en especial de aquellos que van a oírla como si fueran a ver un espectáculo profano, sin compostura en lo exterior y, por supuesto, tampoco interior. La falta de respeto - por ignorancia - se plasmará en la vanagloria de aquellos que dicen oír varias misas a un tiempo o de oír misa y rezar rosarios. Como crítica a todo esto aducirá Villanueva la autoridad de Luis de Granada. Deslinda así las prácticas formales que no sirven, de la verdadera devoción o rectitud que debe dirigir siempre la vida de los cristianos. Sigue la línea

Ibid., Vida Literaria..., 36-37. 
que Erasmo y sus seguidores a lo largo del siglo XVI -León, Granada, Venegas, Porras...- marcaron. Mas Villanueva, como ya hemos señalado, no cita al de Roterdam, sino a los españoles, a los que toma como autoridad segura.

Los cristianos buscan cumplir unos requisitos religiosos, que creen son necesarios y suficientes - propio de la ignorancia en que se encuentran casi siempre- para salvarse, sin preocuparse de nada más. Cuando se les obliga a más se rebelan y aducen que con lo que hacen ya está bien. La causa reside en que todos se paran en la corteza de las cosas, ${ }^{31}$ despreciando el contenido y conformándose con las simples apariencias. Y esto no es sino dejar, según el de Játiva, la ciudad por el camino, el espíritu por la carne, Dios por el mundo...:

Miserable corrupción es, Dios mio, que en las obras exteriores de piedad busque el hombre el cimiento de la religión, el fin y blanco de la vida cristiana, al paso que quebranta la caridad... ${ }^{32}$

Esto no significa otra cosa que quedarse en las hojas y en la corteza, es decir, en la superficie. $Y$ en esto se parecen los cristianos a los judíos que se guiaban por la letra que mata sin atender al espíritu que da la vida, parándose en las figuras y sombras que eran la corteza de los sacrificios y de las ceremonias sin llegar al meollo de la verdad. ${ }^{33}$ Pero, señala, los judíos tenían excusa, porque su fe, su reino y sus esperanzas pertenecían a la tierra; sin embargo, la fe de los cristianos, su esperanza, su reino es celestial y, por tanto, no hay excusa. Ello supone, pues, reducir la piedad a pura exterioridad, sin darse la reforma interior del espíritu:

¡Oh cuántos tienen color y traje de santos y están cien mil leguas de la santidad! Millares de ayunos y de oraciones dará Dios por nulos por falta de intención. ${ }^{34}$

A esta misma corteza se refiere A. Palafox, muy unido a Villanueva en su Carta Pastoral, de 1801 cuando señala que la mayor parte de los fieles no conocen la religión sino por ciertas prácticas exteriores... y que no ven sino la corteza de los actos públicos, pero ignoran el verdadero espíritu.

Villanueva, J. L., Año cristiano, X, 39.

33

34

Ibíd., Dominicas..., II, 429.

Ibíd., Año cristiano, V, dia 22. 
En este sentido es muy explícito, como lo eran Erasmo y Granada con quienes coincide plenamente:

Causa lástima ver cómo algunos rezan recostados, soñolientos y tal vez durmiendo del todo: la costumbre de rezar ha hecho que algunos ni siquiera sepan lo que dicen ni a quién ni para qué. Hablan con Dios y con la Virgen María con menos reverencia de la que guardan a una persona igual y aun inferior a ella en la condición. Todo su afán es rezar el Rosario o muchos rosarios, rezar bien parece que no importa. Esto es reducir la religión a prácticas exteriores, sin procurar la interior reforma del corazón, cuidar de la corteza del árbol y descuidar del meollo. ${ }^{35}$

Esta es la devoción a la que se inclinan. No se quedan tranquilos y temen dejar de rezar un "ave maria" de los que tienen por costumbre pero no temen descuidar la limosna, la buena crianza de sus hijos, seguir sus pasiones, etc. ${ }^{36}$ Esto no es sino puro fariseísmo ${ }^{37}$ y no lleva sino a una falsa concepción del cristianismo que degenera en la corrupción de las costumbres y en un asentamiento de los vicios. ${ }^{38}$ Todo culto exterior se debe ordenar al interior, que es la adoración de Dios en espíritu. No es Dios contrario a los sacrificios exteriores, sino cuando están desprovistos de contenido, de recta intención y apegados a las cosas terrenas más placenteras: ${ }^{39}$

Cuántas obras se ven en algunos cristianos, santos y honestos al parecer, los cuales a los ojos de Dios no son sino sacrificios del demonio, ${ }^{40}$

Ibid., X, 39.

Ibíd., II, 103.

Ibíd., II, 277, ERASmo, Enchiridion o Manual del caballero cristiano, C. S. I. C., Revista de Filología Española, anexo XVI, Madrid, 1971. Hablando de los fariseos que llevan sus franjas de lino en la cabeza con la ley, señala "Hoy es común entre los cristianos llevar al cuello libritos de los Evangelios, la cruz y el rosario y otras tales cosas. Bueno es esto y loable si se hace con el espíritu de piedad, que debe ser el alma de las prácticas exteriores" y que nos lleva a pensar en ERAsmo, Enchiridion..., 249.

Ibid., III, 29.

Ibid., Dominicas..., III, 160. A este respecto señala: «No desecha Dios el sacrificio exterior de los sentidos cuando nace la humildad interior del ánimo. No te pide Dios sangre de animales, sino un corazón puro, ofrecido por la negación evangélica...".

Ibíd., III, 543. 
pues no dejan el mundo para servir a Dios, único camino de salvación. Y recurre Villanueva a la autoridad de Bertrán, en la exigencia de un mayor despego de las diversiones y de los vicios ${ }^{41}$ y volver el rostro a la penitencia. Porque la santidad no consiste sino en hacer la voluntad de Dios en toda su extensión, impidiendo el espíritu de relajación que conlleva el mundo, cuyo seguimiento hace inútil y estéril cualquier devoción, cualquier fe y cualquiera caridad. El que carece de ésta muere espiritualmente, porque no salva la fe sin obras. Esta es la muerte de los malos, que aun teniendo apariencia de vivos, están, sin embargo, muertos.

Es el espíritu rigorista que propone Villanueva como único camino válido; el camino estrecho de la penitencia el que no se tuerce ni por el interés, ni se amedranta por el miedo, ni se dobla por los deleites, ni se deja llevar por la honra. Es el camino en el que el hombre se hace violencia a sí mismo no dando tregua a sus malas inclinaciones, buscando la perfección, la vida espiritual. De forma que la tristeza exterior de la hipocresía es incompatible con la interior de la penitencia.

El hombre está expuesto constantemente al pecado. Por ello ha de esforzarse para no caer y si cae, no dormirse én él, recurriendo constantemente a la oración y al arrepentimiento. La línea que sigue en este tema parece venir de una doble fuente, de Granada y de Bertrán, que al fin y al cabo es la misma, y que le confiere el rigorismo expresado en sus ideas. La mayor parte de los hombres viven sus vidas confiados de que su salvación es segura. De ahí que no hagan caso de la penitencia a la que Dios les llama y difíeran constantemente el arrepentimiento: 


\section{GRANADA}

«¿Acaso dirás, mañana? Ya veo que esta es tu respuesta: dices, mañana me convertiré; después, no ahora. Necesaria me es la conversión, pero aguardo tiempo oportuno: luego, luego, no es cosa ésta para atropellar.

Ya te he oído a ti: óyeme ahora a mí. Si deseas salvarte y confiesas que no convirtiéndote no te puedes salvar, sólo estamos discordes en el tiempo. Tú dices que te convertirás adelante: yo digo que en este instante. Oyeme y verás como tengo razón" ${ }^{42}$

El pecador busca todo tipo de excusas para no convertirse de verdad, pensando que más adelante tendrá tiempo o que Dios le perdonará por su infinita misericordia. Siguiendo con las mismas citas podemos observar el paralelismo:

\section{GRANADA}

"Pues la esperanza de que te perdonará Dios la fundas en su promesa; justo será que en otra igual promesa fundases la esperanza de que te perdonará mañana si le desprecias hoy. Mas ¿dónde te promete eso el Señor? Yo abro la Biblia y veo que los convites del que te quiere perdonar traen siempre prisa. Exhórtate el Señor a que te conviertas a él y juntamente dice que no lo retardes de un día para otro"

\section{VILLANUEVA}

(Para la salvación) «... es necesaria la conversión... Resta, pues, que veamos cuándo ésta se haya de hacer. De manera que no nos quede aquí por averiguar sino sólo el tiempo; porque en todo lo demás no hay debate. Tú dices que adelante te será esto más fácil de hacer; yo digo que luego lo será: veamos quién tiene razón». ${ }^{43}$

42 Fray Luis de Granada, Guía de Pecadores, B. A. E. VI, Madrid, 1944. Guía..., 91-92.

43 Villanueva, J. L., Dominicas..., II. 
Esta falsa seguridad es la que hace que el hombre se olvide por completo del arrepentimiento y consienta con sus pecados, a pesar de que está avisado de juicio. De esta permanencia en el pecado viene todo tipo de males, en opinión de Villanueva. Así, siguiendo también a Luis de Granada y a Bertrán señalará que si bien las tribulaciones personales no siempre son castigo de los pecados, sino también ejercicio de paciencia y crisol de virtud de los justos; pero las calamidades públicas siempre son castigo de los pecados; y esta es una de las verdades más claramente enseñadas por Dios en las Escrituras y en la tradición de la lglesia. De ahí que solicite repetidamente en las mismas Cortes rogativas publicadas para aplacar a Dios. ${ }^{44}$ En términos generales, pues, el hombre no quiere convertirse, prefiriendo permanecer ligado a sus pasiones, que cada vez se hacen mayores:

\section{GRANADA}

"Nace, pues, esta dificultad, no de los impedimentos y embarazos que los hombres imaginan, sino del mal hábito y costumbre de la mala vida pasada; porque con el pecado se oscurece el entendimiento y se enflaquece la voluntad y se desordena el apetito... siendo estos como ruedas de reloj, estando estas ruedas e instrumentos tan maltratados y desordenados..." ${ }^{45}$

\section{VILLANUEVA}

«Esta dificultad de convertirse ahora nace primero del desorden que en ti han añadido tus pecados actuales al transtorno y a la corrupción del original. Triste y lamentable espectáculo eres a los ojos de la fe; ciego en el entendimiento, flaco en la voluntad, desordenado en el apetito; en fin, reloj en todas sus piezas desconcertado" 46

Para seguir en otro lugar:

Sobre estos aspectos habla Villanueva, J. L., Mi viaje a las Cortes, 5. Sobre las rogativas públicas habla HaRo SABATER, J., Pensamiento politicoreligioso..., pero sobre todo LA PARRA, E., Política religiosa de las Cortes de Cádiz. Señala que las Cortes exhortan a todos los clérigos «que para atraer las bendiciones del cielo ordenen oportunamente rogativas privadas y pú- 


\section{GRANADA}

"Pues siendo esto así, en qué seso cabe creer que adelante te será la conversión y mudanza de vida más fácil, ¿cuándo habrás multiplicado tus pecados...? Claro está que adelante estarás más mal habituado cuanto más hubieses pecado. $Y$ adelante estára también el demonio más apoderado de ti y Dios mucho más alejado. Si dices que no puedes ahora vadear este río, aun antes que el río haya crecido mucho, ¿cómo lo pasarás mejor cuando vaya de mar a mar? Si tan trabajoso se te hace arrancar ahora las plantas de los vicios que están en tu ánima recién plantadas, ¿cuánto más lo será adelante cuando hayan echado hondas raíces?". ${ }^{47}$
VILLANUEVA

"Pues si estas causas te hacen ahora difícil la enmienda siendo evidente que con los nuevos pecados suben ellos de punto, sólo estando loco puedes dejar esta empresa para otro día. Si prosigues pecando, se estragará más tu corazón, se hará más fuerte el vicio, quedará el demonio más apoderado de ti y Dios más alejado. Tienes por arduo vadear hoy este río, ¿qué será mañana cuando con las continuas revenidas venga de mar a mar? Parécete ardua empresa arrancar de tu alma las plantas de los vicios cuando aún están recién plantadas, ¿cómo las arrancarás cuando hayan echado en ella hondas raíces?. ${ }^{48}$

blicas, dispongan que sean acompañadas de exhortaciones cristianas y fervorosas, y procuren por todos los medios que dicta la religión y que les inspire su ilustrado celo; el que se reformen las costumbres, se extingan las discordias y se reúnan todos para rechazar al enemigo". Por su parte ViIlanueva en Dominicas..., III, 52 y ss., da cuenta de los escándalos que se producen en las procesiones, que, en principio, son para pedir penitencia y no para hablar, reír, comer, vestir o desnudar imágenes, llevar trajes profanos bordados de oro y plata. Asi se expresa con claridad: "Los que llevan en estas procesiones túnicas negras, como en algunos pueblos se usa, $u$ otra clase de vestidos lúgubres, piensen que este aparato exterior es simbolo de la tristeza interior y del dolor y amargura de la penintencia; y si no corresponde a ellos lo de dentro, dice el M. ${ }^{\circ}$ Avila, a la cual Dios principalmente mira, no será sino ofrecer un cuerpo sin ánima, una cáscara sin meoIlo; y en fin, apariencia sin existencia». No hay ocasión en la que no abunde en el tema de verdadera reforma del hombre. De poco vale lo exterior si no va acompañado de lo inferior, que es lo más costoso y difícil.

Fray luis de Granada, Guía..., 92.

Villanueva, J. L., Dominicas..., II, 53.

Fray luis de Granada, Guía..., 92.

Villanueva, J. L., Dominicas..., II, 54. 
Sin citar ninguna fuente, Villanueva sigue a Luis de Granada en este intento de convencer al creyente de que todos son vanos engaños y astucias del demonio para ir dilatanto una penitencia que exige ya una pronta respuesta por parte suya. La ausencia de esta respuesta está en la nula reflexión de los hombres acerca de este tema. Y cuando vienen a caer en la cuenta ya es demasiado tarde. Pero la penitencia lleva aparejada la corrección de las costumbres, si no es vana, nula y tapadera, simplemente, de la escasa voluntad de conversión. Es decir, el amor a Dios, en palabras de Villanueva, es lo que ha de dirigir la vida del fiel. Pero:

Dirá alguno: si para ser digno de Dios debo amar siempre a Dios más que a mis padres y más que a mí mismo, esto es, sobre todas las cosas; siguese que mientras no llegue a este amor de Dios sobre todas las cosas, no estaré verdaderamente convertido; porque no puede tenerse por convertido a Dios el que no es digno de Dios y no lo es el que así no lo ame. $Y$ aunque en la confesión me arrepienta de mis pecados por temor de las penas del infierno o por otro que no sea este amor de Dios, no podré decir que estoy convertido. A esto responde Fray Luis de Granada diciendo: «No condeno la conversión que comenzó por la consideración de las penas del infierno (como está escrito: conviértanse los pecadores en el infierno, esto es, con la consideración de las eternas penas aparejadas para los impenitentes); y así tampoco los que tienen dolor de que perdieron los bienes de la gracia y de la gloria; mas digo que este dolor no basta para que sea parte de la verdadera penitencia, más de para principio, que pide que sea este dolor principalmente por la majestad divina ofendida y por Dios sobre todo amado. Es bueno este temor para comenzar, mas no para que nos contentemos con este temor, que no nace de caridad, sino del propio amor; y vuestro amor no hace verdadera penitencia sino el de Dios". ${ }^{49}$

Con ello Villanueva clarifica su postura sobre la atrición y contricción, sobre el simple temor al castigo o el amor a Dios. Al mismo tiempo, como buen rigorista y consciente de la poquedad del hombre y su miseria, confía en la fuerza que proviene de Dios para salir de su estado miserable mediante el ejercicio de la oración. De forma que no hay pecador, dirá, que no pueda ser

Ibíd., Año cristiano, Vl, día 5. 
salvo si abandonando el pecado se vuelve a Cristo, ni tampoco hombre justo que no pueda perecer, si solamente confía en si mismo y en sus obras. Todo reside en la forma de responder a Dios.

Nos encontramos con un acentuado rigorismo en sus obras, como exigencia de una vida cristiana que no se anda con paños calientes ni componendas, sino que busca verdaderos remedios a todos los males, vicios y pasiones del hombre que pueda llegar, mediante el amor de Dios, a la perfección cristiana, que es el ideal del creyente. Y en esta línea entiende también Villanueva el ideal de la verdadera sabiduría.

\section{d) El papel religioso de Villanueva en las Cortes}

Lorenzo Villanueva no tuvo ningún tropiezo serio. Contó siempre con los que le podian ayudar, por lo que sus divergenclas y su radicalización en muchas ocasiones no le ocasionaron problemas graves:

Mi gran ventura, que miré siempre como claro indicio de la divina protección, fue que en medio de estas dentelladas de mis émulos, mereci amistad y confianza íntima a los inquisidores Generales". 50

Así sucedió con Felipe Bertrán Rubín de Cevallos, Abad y Sierra, Ramón José de Arce ${ }^{51}$ y finalmente con Lorenzana. Al mismo tiempo mantiene buenas relaciones amistosas.

Su prestigio le servirá de trampolín cuando se declare la Guerra de la Independencia, siendo nombrado por la Junta Central para la comisión eclesiástica que debía preparar las materias de disciplina externa para su posterior estudio en las Cortes. Más tarde en Játiva - su ciudad natal - era elegido diputado a las Cortes por Valencia. ${ }^{52}$ Y será en éstas donde junto con

50 Ibid., Vida literaria..., 75.

51 En defensa de este Inquisidor saldrá Villanueva bajo el seudónimo de Lorenzo Astengo en Carta de un presbitero..., en las que como calificador inquisitorial defiende al Santo Tribunal, aunque sin excesivo celo, pero que resultará polémica, asi como su Catecismo de Estado. Carta de un presbítero español sobre la carta del ciudadano Gregoire, obispo de Blois, al señor arzobispo de Burgos, Madrid, 1798.

52 Haro Sabater, J., Pensamiento político religioso..., 45. 
Serra - valenciano - realice una gran actividad, contradictoria a veces, tanto religiosa como política. De ningún modo se pretendía reducir la religiosidad del pueblo o menoscabar los cimientos de la Iglesia Católica. Su mentalidad, también la de los liberales, es la de que es imposible pensar en una sociedad totalmente secularizada. El papel de la Iglesia no puede desaparecer ni quedar devaluado. Se sigue manteniendo la visión religiosa de la sociedad, aunque con tintes seculares que son los que van a dar sensación de cambio y de progreso. Se busca la reforma de la Iglesia; se quiere un clero más apto para su ministerio, sabio y santo, como se había buscado a lo largo del siglo XViII por parte de ilustrados y reformadores.

Es claro que no vamos a analizar la importancia del hecho religioso en las Cortes de Cádiz, ${ }^{53}$ ni la amplia actividad desarrollada por Villanueva. Solamente nos mueve el interés de enlazarla con la actividad ilustrada anterior por lo que de unión y síntesis tiene y el papel desempeñado por los valencianos. Hay que tener presente que la mentalidad si bien liberal, en aspectos religiosos no es tolerante. No hay emancipación de ciertas formas, esquemas e ideas y se sigue manteniendo una mentalidad tradicional. Así, abolida la Inquisición, propone a la Comisión para proteger la religión católica:

Yo os diré lo que deseáis, lo que yo deseo, y conmigo Santa Teresa, el venerable Granada y todos los prudentes: que la religión católica sea la única en España, que sea protegida por el Soberano, como base de nuestra monarquía, que los que delinquieren contra la fe, sean corregidos por la Iglesia con penitencias y censuras y castigados por la autoridad secular con penas corporis aflictivas. Y esto se conseguirá por el medio llano que propone la comisión. ${ }^{54}$

Pero también es cierto que al tiempo que se busca protección hay evidentes deseos de reforma. $Y$ es en este intento de cambio en el que confluyen una serie de influencias, como la italiana, la francesa, la de la Iglesia de Utrecht o la del Sínodo de Pistoya, por una parte y toda la tradición española y el erasmis-

Estos aspectos han sido estudiados extensamente por LA PARRA, E., en Política religiosa...

54 Haro Sabater, J., Pensamiento político-religioso... 
mo con todos nuestros clásicos del siglo XVI, por otra. En toda esta gama de influencias destaca la figura de Luis de Granada. Hemos visto cómo a través de unos y de otros es recomendado, leído, elogiado, meditado o copiado. Se pretende un cambio de espiritualidad acorde con el mensaje del Evangelio y con la pureza de la Iglesia primitiva. Para que esto sea posible, se necesitan muchas reformas: de los estudios, del clero, de las costumbres y de la Iglesia en general. Dos de los puntos que tratarán las Cortes serán, precisamente, la reforma del clero y la educación o planes de estudios de los seminarios.

Es indiscutible la importancia del clero en la sociedad española, no solamente en el-aspecto religioso, sino también social. Para uno y para otro es necesaria una buena preparación a fin de hacer eficaz su labor y cumplir con decoro sus deberes religiosos como predicación, sacramentos, etc., así como la asistencia social manifestada en la ayuda material a los fieles. La preparación intelectual del clero es básica. Ella ha sido piedra de toque de todos los ilustrados y reformadores del siglo XVIII y que se recogen, con el mismo estilo, en las Cortes. Miembro importante de ellas fue Villanueva. No extrañará, pues, el resultado. Señala La Parra: "La formación intelectual del clero, por consiguiente, era una tarea urgente. Ahora bien, a la hora de exponer las directrices para lograr implantarla, la Memoria, no sólo es explícita cuando se refiere a la "cátedra de elocuencia cristiana", para la que sugiere:

poner como libro fundamental el tratado de la doctrina cristiana de San Agustín; en el caso que pareciese preferible y más oportuna la Retórica de Fray Luis de Granada u otra semejante, sí convendría siempre recomendar la lectura de aquel tratado a los Seminaristas y aun obligarlos a que lo aprendan de memoria. ${ }^{55}$

El texto, señala La Parra, es de enorme importancia; en primer lugar por el interés manifestado por la predicación, y en segundo, por la raíz ideológica del movimiento renovador religioso en la España de principos del siglo XIX. Ahora bien, si observamos atentamente caemos en la cuenta de que la lucha a to largo 
del siglo XVIII no había sido otra que la búsqueda de una perfecta predicación y, casi siempre, de la mano de Luis de Granada, que, a su vez, tiene su foco inspirador en San Agustín, lo mismo que Erasmo y los jansenistas. Pero es importante la actividad de los valencianos y su reponsabilidad en la redacción de la Memoria que confirma, como ya se ha indicado y precisa La Parra, la continuidad de la espiritualidad española del siglo XVI a través del XVIII en las Cortes de Cádiz.

Al clero, una vez salido del Seminario, no se le abandona a su suerte, sino que se busca tenga los medios necesarios para que siga su formación intelectual y no se rompa la cadena iniciada en el seminario. Así se arbitran distintas medidas para que este continuado reciclaje no falte. Por una parte, señala La Parra, la Junta habla de que en cada parroquia se celebren cada semana conferencias sobre teología moral, liturgia y otras materias eclesiásticas:

Estas conferencias son necesarias y oportunas para impedir la ignorancia del clero, para renovar el espíritu eclesiástico, animar a la piedad y hacer florecer la ciencia con la virtud. ${ }^{56}$

Aquí la Junta no hace sino recoger la herencia del siglo XVIII; de las ideas de la mayor parte de los obispos reformadores que buscaban siempre la convivencia de la virtud con la ciencia y ese permanente reciclaje de los que estaban al cuidado de las almas. Por otra parte, pide dotar a las parroquias con las principales obras:

Una Biblia que puede ser la del P. Scio, el Calmet, las obras de San Agustín en su edición de San Mauro, las obras de San Juan Crisóstomo, las de Santo Tomás de Villanueva, una colección general de Concilios, la Suma de los Concilios de España y de los diocesanos, el Concilio de Trento y su Catecismo, el Tomasino, el Cavalieri, las obras de Natal Alejandro, el Gavanto en la edición de Merati y las obras de Fray Luis de Granada. ${ }^{57}$ 
De nuevo hemos de anotar la presencia de Luis de Granada junto con la de Tomás de Villanueva. Extraña la ausencia de nombres como Teresa de Jesús, Luis de León, Luis Vives y otros. Pero lo que está fuera de duda es el carácter reformador de las obras que aparecen y su orientación pastoralista y rigorista, fundamental en la formación de los sacerdotes. 